International Journal of Engineering \& Technology, $7(4.5)(2018) 678-680$
SPC
Snternational Journal of Engineering \& Technology
Website $\frac{w w w . s c i e n c e p u b c o . c o m / i n d e x . p h p / I J E T}{2}$
Research paper

\title{
Tree replanter: a solar powered approach
}

\author{
Aromal V ${ }^{1}$, Gokulnath G. L ${ }^{2}$, Geena Prasad ${ }^{1}$ \\ ${ }^{1}$ Department of Electrical and Electronics Engineering \\ ${ }^{2}$ Department of Mechanical Engineering Amrita Vishwa Vidyapeetham Amritapuri, India \\ *Corresponding author E-mail: aromalvichu1995@gmail.com
}

\begin{abstract}
Tree Transplantation is referred to as the procedure of unearthing the trees and replanting them from one location to another with the objective of re-growing the tree to a new location. This involves moving the tree with the root ball-system thereby protecting while taking up the wider roots. In the proposed design, we use electromagnetic linear actuators working with solar energy instead of hydraulic or pneumatic actuators which consume fossil fuels. Here, a three-blade system is used to unearth the tree wherein the rare blades are opened to encircle the tree and the blades are positioned around the tree to ensure that the root ball is at an equal distance from all sides of the trunk. The blades are closed to remove the tree with the root ball intact. The tree with the spade is adjusted to the truck for safe transport.
\end{abstract}

Keywords: Electromagnetic Linear Actuator; Three Blade System; Tree Replanter.

\section{Introduction}

Trees reduce runoff by breaking rainfall, thus allowing the water to flow down to the earth and this prevents the storm water from carrying the pollutants to the ocean. Trees acts as shelter in highways. By absorbing carbon dioxide in the atmosphere, trees help in reducing the global warming. Thus cutting of trees from road sides or construction sites will inversely affect the environment Hence the idea of tree transplantation comes into act. In the world of rapid growth, tree replanter comes in handy to save trees. The construction of roads or buildings will no longer affect a tree. Usually a replanter system consists of 3 or 4 blades, even single or dual blade designs also exist [16]. The blades in the system are used to hold the trees including the soil out of the ground and place the tree in the desired location [1]. For commercial tree nursery operations, similar machines are used. There are various types of spades with different sizes that are available in the market, which can be used for wide-range soil conditions. Here, in this project, a tree replanting system runs on the electromagnetic linear actuator is employed to control the three-blade system to uproot the tree. Electromagnetic linear Actuators are light weight and energy efficient compared to hydraulic or pneumatic actuators Hydraulic and pneumatic actuators use fossil fuel, which is a nonrenewable fuel [17]. The electromagnetic linear actuators make use of solar energy which is non-polluting and renewable source and therefore more efficient which is discussed in this project. The root ball system of the trees are typically $0.8-1.2 \mathrm{~m}$ deep, wrapped and wired to protect the tree during transportation. Canopy pruning is mainly specified with the balancing of root loss while leaving sufficient roots for re-growth [9]. Trees can be lifted with the help of straps, wrapping the root as well as the mid trunk. The trunk diameter is used for determining the tree root spread. These uprooted trees are transported to the temporary sites and set at $5 \mathrm{~m}$ spacing in a specially constructed ground [6]. Geo-fabric wire meshes are mainly used as planter boxes, which is $1 \mathrm{~m}$ to $1.4 \mathrm{~m}$ high and 20 to $30 \%$ wider than the root ball [3]. The planter box helps to monitor the transplanted trees, so it helps to examine the root growth without disturbing the tree. Also it ensures the free drainage of the root ball with mulch retained and thus competition among the weeds can be minimized. Therefore, trees are guyed to ensure the stability in high speed winds. The planter box provides monitoring of arboriculture practices which includes irrigation, mulching, weeding, fertilizing, and disease and pest control [3]. For placing the trees in the fleapit, some factors has to be considered such as rooting the plant in the hole. Planting the trees at the proper depth (1/3rd of the ball can be above the existing grade).

For eliminating the air pockets backfill it firmly and should come right up to the root ball. The characteristics of the tree and its growing conditions are given figure $1[3]$.

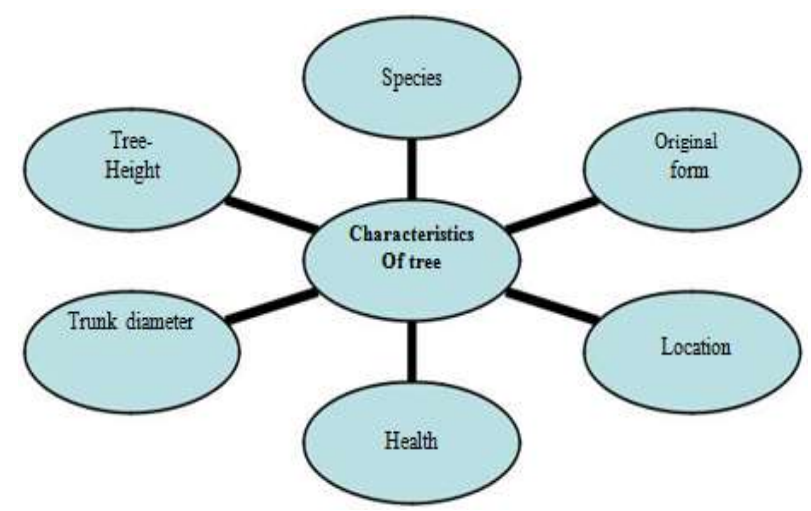

Fig. 1: Characteristics of the Tree.

\section{Process of transplantation}

The trees are uprooted in advance for transplantation in three different steps. (a) Digging of the root which is done by hand. (b)The depth of the root may reflect variably among the soil profiles as well as in different tree species (c). 
The specific details of the transplanting operation are: (a) time period of the first root pruning should be at least 2 month intervals (b) Canopy pruning (percentage reduction in canopy volume) (c) trees should not suffer damage during transplanting.

\section{Process flow chart}

The process flow of the tree replantation is given in figure 3 . The various steps involved are initial preparation, soil condition, root ball preparation, monitoring, transplantation and post transplantation [3]. The flow chart given in figure 2 explains in details the various steps:

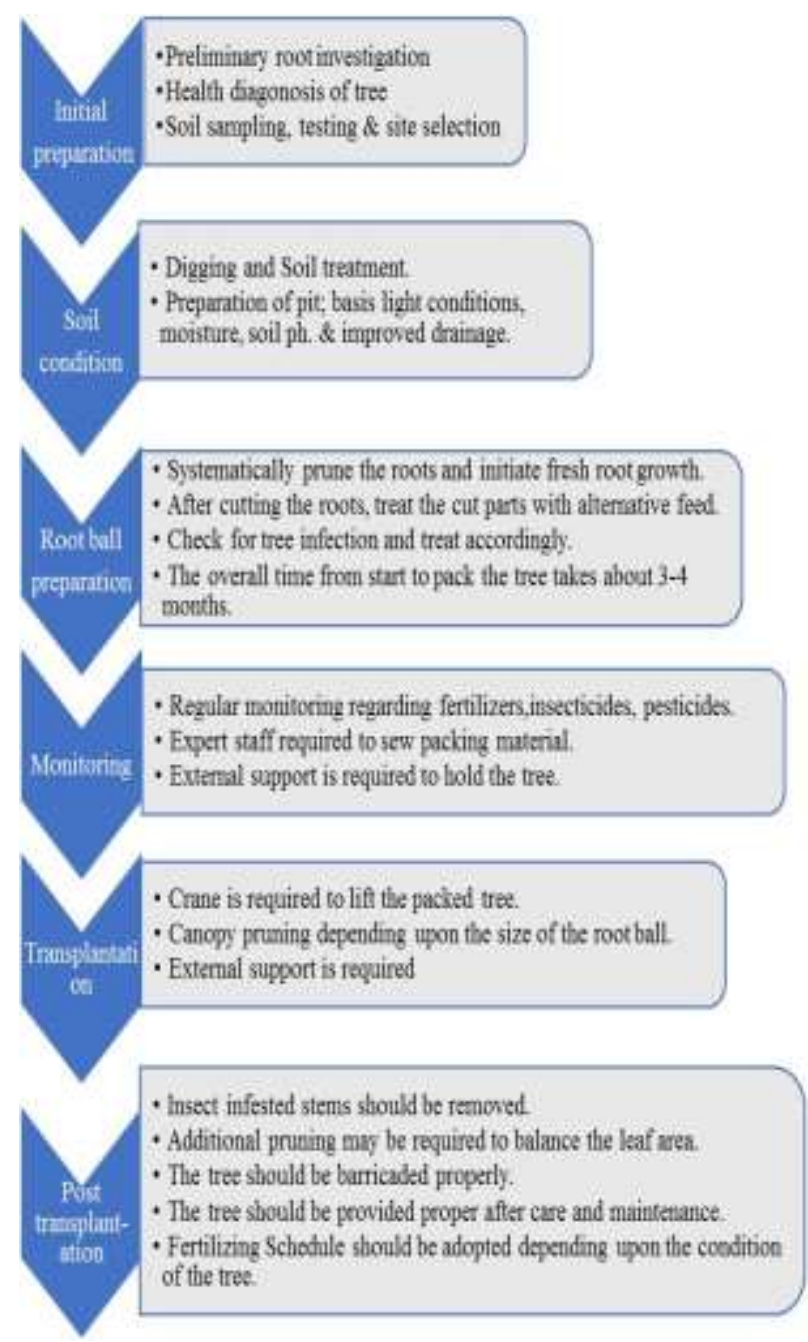

Fig. 2: Process Flow Chart.

\section{Challenges}

The tree transplantation is a viable and an innovative option. However, being a relatively new concept in India, it comes with its own set of challenges spanning across costing, survival over long timeframes, location, distance between the transplantation source and destination sites, higher preparation time and lack of skilled workforce and technology [7]

\subsection{Cost}

The first challenge in the tree replanting is its cost and effort that is involved in the transplanting work [10].

As considerable time, efforts and cost will be involved in the tree transplanting work and the tree will inevitably face difficulties for its regenerating growth, it is necessary to consider if the contribution of the tree after transplanting is proportionate to the cost [10]. Transplantation of trees, specially the more matured ones have a big engineering feat. It takes specialized people and equipments to perform these activities and the rate of such equipments and specific workforce is generally high. Besides this, the cost depends on different variables considering the following parameters such as size and age of the tree [8], equipment being used and the distance travelled from the source to destination site.

\subsection{Survival rate}

The survival rate of the transplanted trees also remains a challenge. The experiences in Gujarat show that the survival rate is as low as $5 \%$ and as high as $85 \%$ [5]. The higher survival rate not only gives the confidence to the proponents about the effectiveness of the method but also reduces the cost of successful transplantation for the agencies undertaking such activities. Some global studies shows that the survival rate of small-caliper tree have better sur-vival rate than large-caliper tree (0:58\%) [11]. Some of the key factors that impact the survival rate of the transplanted trees are soil and climatic conditions of the place [8], season of transplant, preparation method and time.

\subsection{Technology}

There are various know-hows available in the market with the tree transplantation, starting from traditional to ultra-modern. But in India, transplantation process often requires big machines and hence it entails a lengthy process which creates traffic problem. Again here the challenge is the cost of large transplanting equipment, which cost more than INR 1 crore making them unaffordable to small agencies. The improvement what the project highlighted here is with the actuators (Actuators or power transducers provide output mechanical work from input energy and here the input energy is the control variable and output mechanical work is the acting variable) [12]. In this project, an electromagnetic linear actuators is proposed instead of traditional actuators like pneumatic and hydraulic actuators, because electromagnetic linear actuators are light weight and energy efficient compared to other actuators.

In electromagnetic actuators, the control variable is the electric current and the acting variable is the force interaction and its effects. The main principle of the transformation in these actuators is the force interaction in the magnetic field [12].These actuators can be networked and reprogrammed at a fast pace. The encoders in these actuators are used to control the velocity, position, torque and applied force [17]. The other add-up of this project is the installation of solar panels on the top of the truck. The normal rating of solar panel used in heavy trucks is about 95W [6].

Solar flex is used as solar panel and these light weight panel can be affixed with adhesive or screws. It has durable surface which measures less than $3 \mathrm{~mm}$ thickness and avoids custom mounts. This flexible nature makes it easy to be installed in any curved surface which provides complete output with any future loss. Monocrystalline is used as it is the most efficient material. The output efficiency has a warranty of 5 years [13]. Solar controllers are used for controlling the current flow. Here, the rating of the solar panel used in this model is estimated with following specifications:

Type: FLEX-100

Current: $30 \mathrm{~A}$

Power: $160 \mathrm{~W}$

Solid works 2015 version software is used for designing the solar tree replanter. Solid works is a solid modeling computer-aided design (CAD) and computer aided engineering (CAE) computer program that runs on Microsoft windows [14]. For this project we utilize a parametric feature-based approach for modeling and assembling the solar tree replanter. It can be either numeric parameters, such as line length or circle diameters, or geometric parameters, such as tangent, parallel, concentric, horizontal or vertical etc and its features refer to the building blocks of the part. The shape based features typically begin with a 2-D or 3-D sketch of shapes such as bosses, holes, slots, etc and these shapes are then 
extruded to add or remove material from the part. The pro-posed model is a 3-D sketch consisting of solar powered 3 spade model and it is shown below in figure 3 .

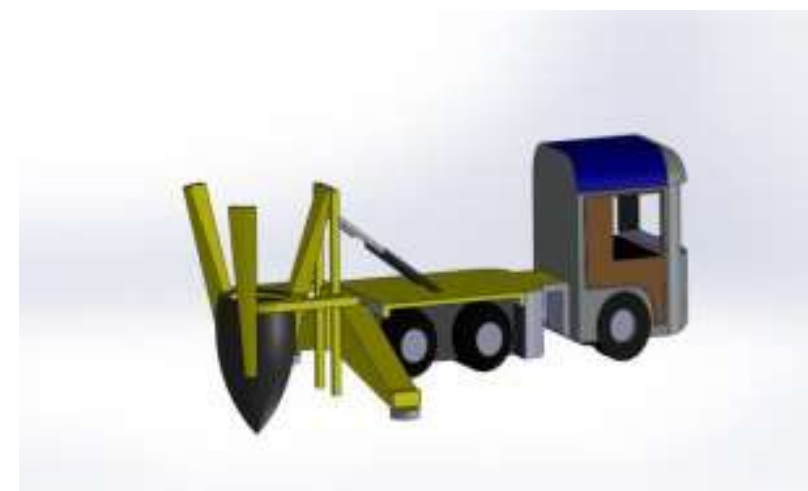

Fig. 3: Solid Works 3D-Model of a Tree Replanter.

There are various type and size of tree spades and these spades has the capacity to move a tree with maximum trunk diameter of eight to ten inches. In order to move a tree, the trade size analysis is required and in case of deciduous trees analysis is done by measuring the trunk diameter whereas in case of evergreens, anal-ysis is done by measuring the tree height. The trunk diameters are measured by using a caliper, six inches above the ground for four inches in diameter or smaller tree and 12 inches above the ground for trees with a large diameter

\section{Conclusion}

India has limited experience in tree transplantations and researches are needed to assess its feasibility. The main reason of transplantation failure in India is because of the cost intensive and requirement of heavy machines [15]. The accessibility of trees to be transplanted along highways is one of the main issues. The 4bladed tree replanting system with heavy weight hydrau-lic actuators thus proved lethal for a budding initiative. Here in this project, electromagnetic linear actuators with 3-bladed sys-tem hence proved to be handy because of its low weight and cost. Due to the limitation of fossil fuel, the use of solar panel is im-plemented and hence the solar power reduces the environmental pollution.

\section{References}

[1] Balaji A, Jahir Hussain H, Faheem Ashkar M R, Gowsick C S, Subakar K, Design and Fabrication of Agro-based Automatic Plantain Tree Cutting Machine,2015, vol.4 Issue 3, pp. 1767-1770.

[2] Harris R.W, Clark J.R \& Matheny N.P, Arboriculture-Integrated Management of Landscape Trees, Shrubs \&Vines, New Jer-sey: Pearson education, Inc., 2004.

[3] Himanshu Sekhar, Transplanting growth : Greening our highways, Chandan Bhavanani, 2016

[4] Jagdish Prasad, Transplantation along National Highways, APCCF, 2016.

[5] Rohith Nursery, New Delhi; http://www.treetransplantation.in/ last accessed Nov15, 2017.

[6] Susan D Day, P. Eric Wiseman, Sarah B. Dickinson \& J.Roger Harris, Contemporary concepts of root system architecture of urban trees, July 2010.

[7] Watson G.W\& Himelick E.B, Journal of Arboriculture 8(9) pg. 225-229, 1982

[8] Watson G.W\& Himelick E.B, Principle and practice of planting trees and shrubs, International society of Arboriculture, 1997.

[9] Watson G.W\& Himelick E.B, Principle and practice of transplanting tree, 2013.

[10] Development Bureau, Guidelines for tree transplanting, Hong Kong Government, 2014.

[11] Daniel K.Struve, Laura Burchfield, Cathy Maupin, Survival and growth of transplanted large and small caliper red oaks, 2000.

[12] http:// www.agros2d.org/electromagnetic-actuators/last accessed on Dec 05, 2017
[13] http://www.gpelectric.com/products/solar-flex-kits-modules/last accessed on Nov 25, 2017.

[14] http://www.solidworks.com SOLIDWORKS 2013, version.23, last accessed on November $15^{\text {th }} 2017$.

[15] The Energy Research Institute, Transplantations along National Highways as a measure for carbon sequestration, Indian habi-tat centre, New Delhi, 2016.

[16] http:// www.revolvy.com/ tree spades/last accessed Nov 20, 2017.

[17] http://www.machinedesign.com/linear-motion/ last accessed on Nov20, 2017. 